\title{
Experimental Comparison of Bovine-Derived Xenograft, Xenograft-Autologous Bone Marrow and Autogenous Bone Graft for the Treatment of Bony Defects in the Rabbit Ulna
}

\author{
Davut Keskin $^{a} \quad$ Cemal Gündoğdu ${ }^{b} \quad$ Alpaslan Cevdet Atac ${ }^{a}$ \\ Departments of a Orthopedics and Traumatology and ${ }^{b}$ Pathology, Faculty of Medicine, Atatürk University, \\ Erzurum, Turkey
}

\section{Key Words}

Bony defect $\cdot$ Xenograft $\cdot$ Bone marrow $\cdot$ Autogenous graft

\begin{abstract}
Objectives: The purpose of this study was to determine whether bone marrow grafted percutanously has an effect on the healing of bony defects filled with bone-derived xenografts. Materials and Methods: Eighty New Zealand albino rabbits with an average age of approximately 1 year were divided into 4 groups, each consisting of 20 animals. Bony defect was induced in the ulnas of all rabbits by excising a $1-\mathrm{cm}$-long bone segment from the $3-\mathrm{cm}$ proximal segment of the right distal radioulnar joint. Bone defects were treated simultaneously with bovine-derived xenograft, a combination of xenograft and bone marrow or on the 5th day following the filling of the segment with the xenograft and autogenous bone graft. Treatment results obtained for each application type were compared with each other with regard to the radiological, biochemical and histological criteria. Results: No significant statistical differences were determined between the groups in their 15th-day radiographs. The group treated with only xenograft from the first month onwards presented with the worst results and was significantly different from the other groups with respect to all evaluation criteria. No statistically significant difference was determined between rabbits treated with xenograft and bone marrow combination and with autogenous bone graft.
\end{abstract}

Conclusions: This study revealed that when xenografts are combined with autologous bone marrow, their incorporation into the host bed accelerates significantly.

Copyright $\odot 2007$ S. Karger AG, Basel

\section{Introduction}

Treatment of bony defects has always been an important challenge for orthopedic surgeons. Filling the defect area with bone graft is one of the most widely used treatment methods [1]. Autogenous bone grafts are considered the most appropriate graft type for this purpose. Need frequently arises, however, for alternative bone grafts due to limited availability of autogenous bone graft [2-4]. Xenografts, allografts and calcium ceramics are graft materials that can substitute for autografts but are not as effective. Xenografts have a low cost and high availability but have not been preferred, due to poor outcome [5].

Bone marrow, found in abundance and easily procured to treat various bone pathologies, does not possess osteoconductive property and is therefore not sufficient to fill bone defects [6-9]. Used in combination with bone grafts or calcium ceramics, bone marrow or osteoblasts derived from the bone marrow have been found to yield a good outcome in bone pathologies that require osteogenesis [10-13]. The question was whether the addition 
of bone marrow would compensate for the poor biological capacity of a xenograft. Treatment with a combination of autologous bone marrow and xenograft has been shown to yield a good outcome in bone defects, but some bone pathologies have occurred [10, 14-18]. However, there are insufficient data whether or not xenografts produced with the most recent technology would offer a success similar to autografts when combined with autologous bone marrow. The primary aim of this study was to establish whether or not xenografts coupled with bone marrow was as effective a treatment of bone defects as autografts. We suggest that there are insufficient studies indicating the success presented by xenografts produced by today's technology when combined with autologous bone marrow in comparison to that achieved by autografts. This study was planned and conducted to compare the two procedures.

\section{Materials and Methods}

A total of 80 New Zealand albino rabbits, with an average age of 1 year (11-13 months) and average weight of $2.9 \mathrm{~kg}(2.2-3.8)$ were divided into 4 groups, each composed of 20 animals. The rabbits were anesthetized with a combination of ketamine and xylazin administered by intramuscular injection. The ulna was accessed in all rabbits through a longitudinal incision of approximately $2-3 \mathrm{~cm}$ performed $3 \mathrm{~cm}$ proximal to the right distal radioulnar joint. Bone defect was induced by excising a $1-\mathrm{cm}-$ long bone segment using a $15,000 \mathrm{rev} / \mathrm{min}$ hand drill with a circular diamond bit and cooling with normal saline solution. In the first group, the defect was then filled with bovine-derived cancellous chip graft (Unilab surgibone ${ }^{\circledR}$; Unilab Surgibone Inc., Mississauga, Ont., Canada); in the second group with bovine-derived cancellous chip graft followed on the 5 th day by percutaneous injection into the defect area with the autologous bone marrow aspirated from the medullary cavity of the femur on the 5th day after the first operation; in the third group with autogenous cancellous bone graft taken from iliac bone; in the fourth group with bovinederived cancellous chip graft and a simultaneous percutaneous injection of autologous bone marrow performed during the same operation after suturing the skin. Since the radius was left untouched, no internal or external fixation was needed. The first half of each group was sacrificed at the end of the first month and the other half at the end of the second month with intravenous sodium thiopental.

Immediately after completion of all operations at 2 and 4 weeks, the rabbits were checked radiologically with additional examinations in 40 rabbits at 6 and 8 weeks. Biomechanical histological evaluations were performed in the ulnas of the sacrificed subjects and tissues were taken for histological examination.

Obtaining Bone Marrow and Injection to Defect Site

An 18-gauge needle used to aspirate the marrow was pushed from the left fossa trochanterica towards the medullary cavity of the femur, and its injector piston was retracted by pressure to ob- tain red marrow of $2 \mathrm{~cm}^{3}$ volume. The sample was heparinized and examined with a light microscope. After the bone marrow had been confirmed, it was injected percutaneously to the defect site in the ulna of the rabbits. Following these injections, a fusiform swelling was observed in the bony defect sites, without any leakage from the incision sites. For group 2 rabbits, percutaneous bone marrow injection was performed on the 5 th day following bone grafting, while for the 4 th group, it was performed simultaneously with bone grafting.

\section{Obtaining Cancellous Bone Graft from the Iliac Bone}

Following the bone defect inducement in group 3 rabbits, an approximately $3-\mathrm{cm}$ incision was made over the left iliac crest to the iliac bone, which was well-exposed by removing soft tissues. Part of the outer cortical layer was removed by an osteotome, and a sufficient quantity of cancellous bone graft was obtained by a curette. The autogenous cancellous bone graft obtained in this way was then used to fill the defect induced in the ulna.

\section{Radiological Evaluation}

All radiographs were taken by keeping the forearms of the animals $15 \mathrm{~cm}$ above the extremity in an anteroposterior position, using a Siemens Polyphos 300 E model machine and applying a $42-\mathrm{kV}, 2.5-\mathrm{mAs}$ dose at a distance of $100 \mathrm{~cm}$, with $24 \times 30 \mathrm{~cm}$ Kodak $^{\circledR} 100$ Nif MXG film cassettes. A scoring system developed by Lane and Sandhu [1] was utilized for the evaluation of the radiographs (no evidence of bone formation: 0 points; bone formation occupying $25 \%$ of defect: 1 point; bone formation occupying $50 \%$ of defect: 2 points; bone formation occupying $75 \%$ of defect: 3 points; full gap bone formation: 4 points).

\section{Biomechanical Evaluation}

After sacrificing the animals, the radius and ulna were removed as a unit with the disarticulation of radiocarpal and humeroulnar joints in a manner not to cause damage to the defect areas. Soft tissues were dissected carefully. After passing a $2.5-\mathrm{mm}$ Kirschner wire transversely on both ends of the ulna, both distal and proximal ends were embedded in methylmetacrylate in a manner to keep the far ends of the Kirschner wire outside. The average of the diameters (d) of the proximal, middle and distal sections of the defect area was calculated. The surface area of the sections was determined in square centimeters using the formula

$$
\text { area }=\frac{\pi d^{2}}{4}
$$

Then a mechanical universal test machine with a capacity of $5 \mathrm{t}$, capable of applying a traction force with $0.25 \mathrm{~kg}$ accuracy at a speed of 5-20 $\mathrm{mm} / \mathrm{min}$, was used to measure break force. Loading speed was applied as $5 \mathrm{~mm} / \mathrm{min}$. Kirschner wires connected to the distal and proximal ends were fixed via chains to the upper and lower test rig, respectively, used for force measurement in the universal test machine. All ulnas subjected to bone defects were broken from the defect area under the tensile strength, which was calculated as the division of break load by lesion area in newtons per square centimeter. During biomechanical assessment, it was observed that fractures occurred at the gap regions, which was also confirmed by histological examination.

\section{Histological Evaluation}

After the biomechanical test, the bones were fixed in buffered $10 \%$ formaldehyde solution for $24 \mathrm{~h}$. Fixed bone tissue was 
Table 1. Histological scoring

\begin{tabular}{llll}
\hline & \multicolumn{2}{l}{ Point } & Point \\
\hline Union & & Marrow & \\
No evidence of union & 0 & None & 0 \\
Fibrous union & 1 & Beginning to appear & 1 \\
Osteochondral union & 2 & More than one half of bony defect & 2 \\
Bone union & 3 & Complete colonization of red marrow & 3 \\
Complete reorganization of shaft & 4 & Adult-type fatty marrow & 4 \\
\hline Spongiosa & & Cortex & 0 \\
No osseous cellular activity & 0 & None & 1 \\
Early apposition of new bone & 1 & Early appearance & 2 \\
Active apposition of new bone & 2 & Formation under way & 3 \\
Reorganizing spongiosa & 3 & Mostly reorganized & 4 \\
Completely reorganized spongiosa & 4 & Completely formed & \\
\hline
\end{tabular}

decalcified in $5 \%$ nitric acid for a period of $24 \mathrm{~h}$, followed by deacidification under tap water. Increasing degrees of dehydration were applied using alcohol. Following treatment with xylol, they were embedded in paraffin blocks and let cool. After the preparations had been molded, longitudinal sections at a thickness of 3-5 $\mu \mathrm{m}$ were cut with a microtome, ensuring coverage of defective and normal bone regions. The sections were then stained with eosin and examined under a light microscope. Histological evaluation was based on union, spongiosa, cortex and bone marrow formation. For this procedure, a histological scoring system developed by Lane and Sandhu [1] and Heiple et al. [14] was used (table 1).

\section{Statistical Analyses}

One-way ANOVA was used to determine if there was any difference regarding the results of radiological, biomechanical and histological evaluation, with Duncan's multiple range test being applied in cases where a difference was observed. A p value $<0.05$ was considered significant, while $\mathrm{p}<0.01$ was regarded as very significant and $\mathrm{p}>0.05$ nonsignificant. SPSS software, version 11.5, was used in order to perform statistical evaluations (SPSS, Chicago, Ill., USA).

\section{Results}

\section{Radiological Findings}

No significant difference was found in bone formation on 15th-day radiographs of all rabbits ( $p>0.05$ ). Group 1 was the worst, as observed in the radiographs taken on the 30th, 45th and 60th day (30th day: $\mathrm{p}<0.05 ; 45$ th and 60th: $\mathrm{p}<0.01$ ); there was no significant difference among the other groups (table 2, fig. 1).

\section{Biomechanical Findings}

Group 1 had the least mean tensile strength among the rabbits sacrificed at the end of the first month $(\mathrm{p}<0.01)$, while there was no significant difference among the other groups $(p>0.05)$. Also, group 1 had the lowest mean tensile strength among those sacrificed at the end of the second month ( $p<0.01)$. Group 2 had the second lowest mean tensile strength. There was a significant difference between groups 2 and 3 ( $\mathrm{p}<0.01$ ); no difference, however, was detected between groups 2 and 4 . While there was no significant difference between group 3 and group 4 ( $p>0.05$ ), group 3 had the best scores among all groups (table 3).

\section{Histological Findings}

At the end of the first month, group 1 was significantly different from the others with respect to union, spongiosa, cortex and bone marrow formation as well as total scores $(\mathrm{p}<0.01)$ and had the lowest histologic scores. There was no significant difference between groups 2,3 and $4(\mathrm{p}>0.05)$. Of the rabbits sacrificed at the end of the second month, group 1 was again the worst, significantly differing from the others $(\mathrm{p}<0.01)$, whereas there were no significant differences between the other groups $(p>0.05)$ with respect to union, cortex and total score parameters. While group 1 was the worst and group 4 was the best with respect to spongiosa formation, groups 1 and 4 had the worst scores and group 2 the best scores with respect to formation of bone marrow (table 4 , fig. 2).

\section{Discussion}

Bone grafts should have osteogenic, osteoinductive and osteoconductive properties to achieve success in grafting $[2,3,15]$. Autogenous cancellous bone grafts are 

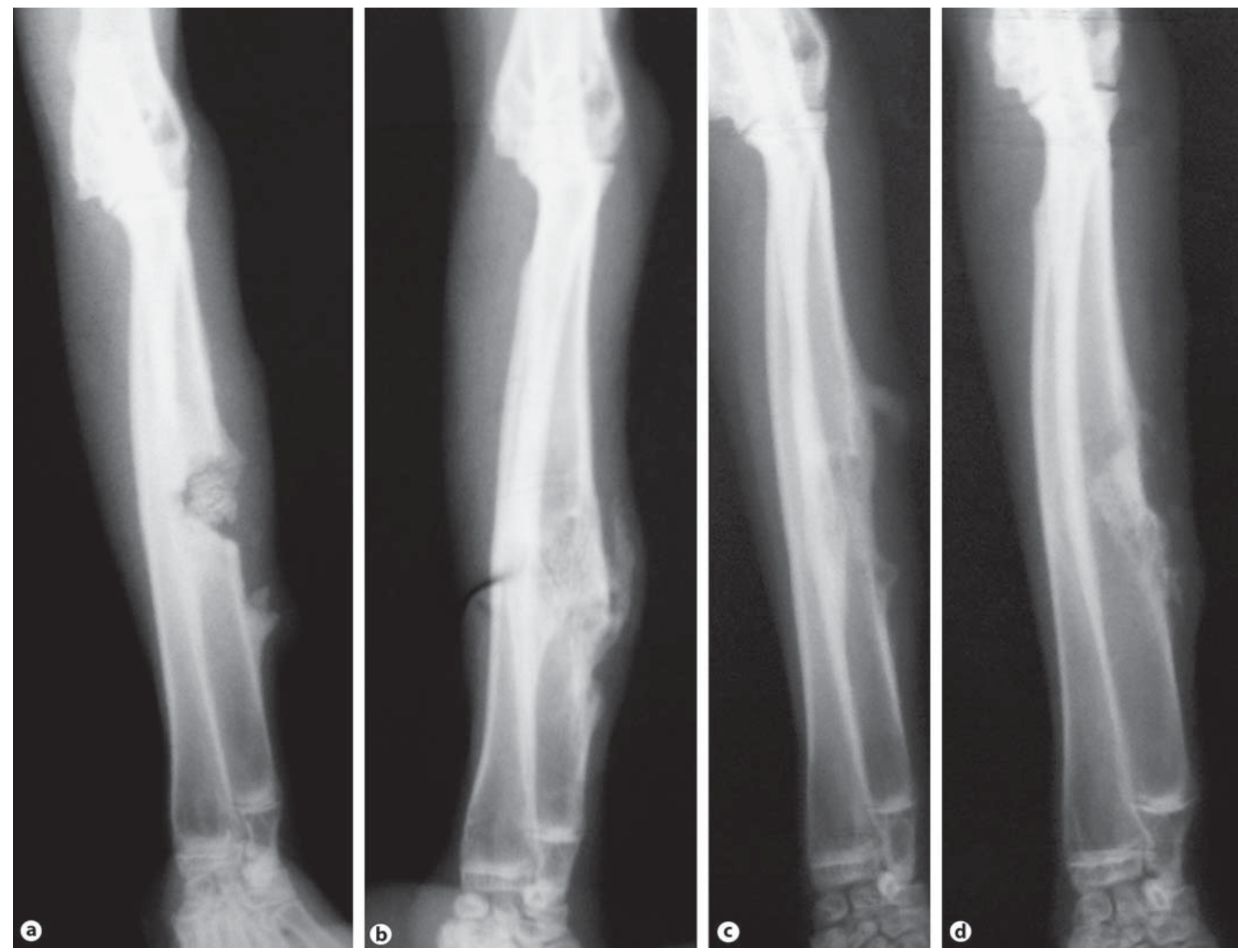

Fig. 1. Radiograph at 2 months for each group: group 1 (a), group 2 (b), group 3 (c), group 4 (d).

Table 2. Comparison of radiographic outcomes between the groups

\begin{tabular}{lllll}
\hline Group & \multicolumn{4}{l}{ Radiographic scores } \\
\cline { 2 - 5 } & $\begin{array}{l}\text { day 15 } \\
\text { (nonsignificant) }\end{array}$ & $\begin{array}{l}\text { day } 30 \\
(\mathrm{p}<0.05)\end{array}$ & $\begin{array}{l}\text { day 45 } \\
(\mathrm{p}<0.01)\end{array}$ & $\begin{array}{l}\text { day 60 } \\
(\mathrm{p}<0.01)\end{array}$ \\
\hline 1 & $0.00 \pm 0.00^{\mathrm{a}}$ & $0.40 \pm 0.52^{\mathrm{b}}$ & $0.50 \pm 0.53^{\mathrm{b}}$ & $0.90 \pm 0.32^{\mathrm{b}}$ \\
2 & $0.20 \pm 0.42^{\mathrm{a}}$ & $2.20 \pm 1.23^{\mathrm{a}}$ & $3.10 \pm 1.10^{\mathrm{a}}$ & $3.30 \pm 0.95^{\mathrm{a}}$ \\
3 & $0.30 \pm 0.67^{\mathrm{a}}$ & $1.70 \pm 1.16^{\mathrm{a}}$ & $2.80 \pm 1.03^{\mathrm{a}}$ & $3.30 \pm 0.82^{\mathrm{a}}$ \\
4 & $0.10 \pm 0.32^{\mathrm{a}}$ & $2.10 \pm 1.20^{\mathrm{a}}$ & $3.00 \pm 1.15^{\mathrm{a}}$ & $3.30 \pm 0.95^{\mathrm{a}}$
\end{tabular}

Values are means \pm SD. Whereas differences between values marked with identical letters are not statistically significant, the other differences are significant.
Table 3. Comparison of biomechanical outcomes between the groups

\begin{tabular}{lll}
\hline Group & \multicolumn{2}{l}{ Tension force, $\mathrm{N} / \mathrm{cm}^{2}$} \\
\cline { 2 - 3 } & day 30 & day 60 \\
\hline 1 & $114.50 \pm 7.40^{\mathrm{b}}$ & $275.00 \pm 26.67^{\mathrm{c}}$ \\
2 & $350.00 \pm 90.00^{\mathrm{a}}$ & $436.00 \pm 96.86^{\mathrm{b}}$ \\
3 & $325.00 \pm 108.17^{\mathrm{a}}$ & $555.00 \pm 156.51^{\mathrm{a}}$ \\
4 & $280.00 \pm 79.93^{\mathrm{a}}$ & $465.00 \pm 118.95^{\mathrm{a}, \mathrm{b}}$ \\
\hline
\end{tabular}

Values are means $\pm \mathrm{SD}$. Whereas differences between values marked with identical letters are not statistically significant, the other differences are significant. $\mathrm{p}<0.01$. 

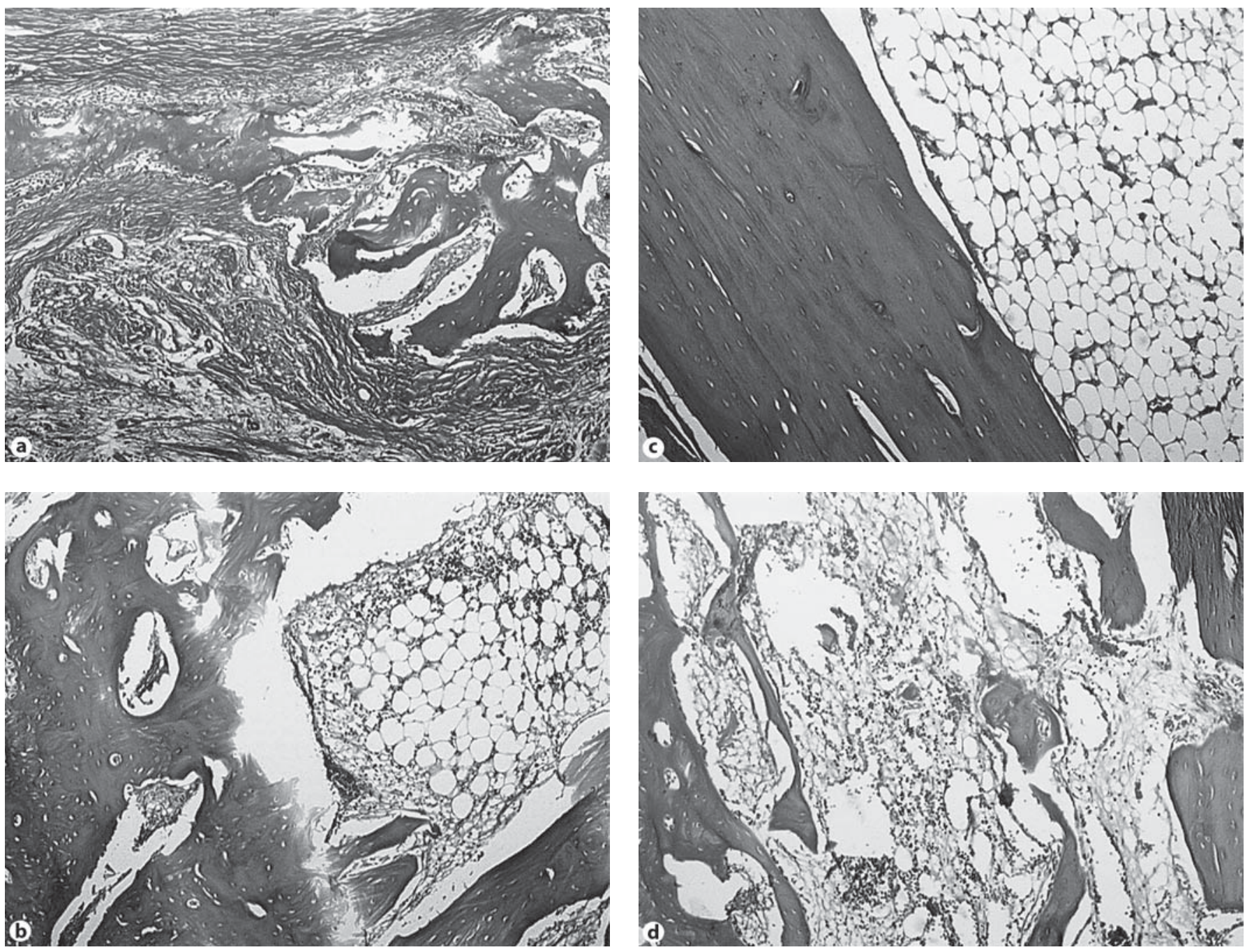

Fig. 2. Examples of specimens of the second month for histologic findings. Group 1 (a): osteochondral union, early apposition of new spongious bone, no cortical formation, marrow beginning to appear in fibrous tissue. Group 2 (b), group 3 (c) and group 4 (d): bone union, mostly reorganizing spongiosa, cortical formation, complete colonization of red marrow. HE. $\times 40$.

ideal grafting materials possessing all 3 features $[2,3$, 15]. No other material has yet been discovered to incorporate these features as well as autograft. However, new and alternative grafting methods are needed, since the sources of autograft are limited and autografts involve additional surgical interventions, increased blood loss, extended operation time and weaken donor bone structure [2-4]. Xenografts, allografts and calcium ceramics that include coral and C-P ceramics, growth factors (BMPs, TGF- $\beta$, insulin-like growth factors, fibroblast growth factors, ILs, granulocyte colony-stimulating factors and granulocyte-macrophage colony-stimulating factors) are substances that have been and are being used as substitutes for autografts [4]. Though slim, allografts carry a risk of transmitting viral infection despite modern sterilization and storage methods [4] and are not always available. The cost of processed and ready-to-use allografts is high. Biological ceramics that constitute a scaffold for new bone formation and growth factors that modulate the differentiation of mesenchymal stem cells to osteoprogenitor cells are expensive. Furthermore, growth factors lack osteoconductive property.

Xenografts lose their osteogenic and osteoinductive properties during chemical cleaning performed to coun- 
Table 4. Comparison of histological outcomes between the groups

\begin{tabular}{|c|c|c|c|c|c|}
\hline \multirow[t]{2}{*}{ Group } & \multicolumn{5}{|c|}{ Histologic scores } \\
\hline & union & spongiosa & cortex & marrow & total \\
\hline \multicolumn{6}{|c|}{ Rabbits sacrificed after the first month } \\
\hline 1 & $0.40 \pm 0.52^{\mathrm{b}}$ & $0.70 \pm 0.48^{\mathrm{b}}$ & $0.00 \pm 0.00^{\mathrm{b}}$ & $0.50 \pm 0.53^{\mathrm{b}}$ & $1.60 \pm 1.35^{\mathrm{b}}$ \\
\hline 2 & $2.00 \pm 0.47^{\mathrm{a}}$ & $2.70 \pm 0.48^{\mathrm{a}}$ & $1.30 \pm 0.82^{\mathrm{a}}$ & $1.80 \pm 0.79^{\mathrm{a}}$ & $7.80 \pm 1.55^{\mathrm{a}}$ \\
\hline 3 & $1.70 \pm 0.48^{\mathrm{a}}$ & $2.50 \pm 0.85^{\mathrm{a}}$ & $1.20 \pm 0.79^{a}$ & $2.10 \pm 0.88^{\mathrm{a}}$ & $7.50 \pm 1.58^{\mathrm{a}}$ \\
\hline 4 & $1.80 \pm 0.79^{\mathrm{a}}$ & $2.60 \pm 0.52^{\mathrm{a}}$ & $1.10 \pm 0.57^{\mathrm{a}}$ & $1.70 \pm 0.67^{\mathrm{a}}$ & $7.20 \pm 1.99^{\mathrm{a}}$ \\
\hline \multicolumn{6}{|c|}{ Rabbits sacrificed after the second month } \\
\hline 1 & $1.40 \pm 0.52^{\mathrm{b}}$ & $1.70 \pm 0.48^{c}$ & $0.20 \pm 0.42^{\mathrm{b}}$ & $1.80 \pm 0.42^{\mathrm{c}}$ & $5.10 \pm 1.10^{\mathrm{b}}$ \\
\hline 2 & $2.60 \pm 0.52^{\mathrm{a}}$ & $2.60 \pm 0.52^{b}$ & $2.10 \pm 0.32^{\mathrm{a}}$ & $2.80 \pm 0.42^{\mathrm{a}}$ & $10.10 \pm 1.45^{\mathrm{a}}$ \\
\hline 3 & $2.60 \pm 0.52^{\mathrm{a}}$ & $2.80 \pm 0.42^{\mathrm{a}}$ & $2.40 \pm 0.52^{\mathrm{a}}$ & $2.40 \pm 0.52^{\mathrm{a}, \mathrm{b}}$ & $10.20 \pm 1.40^{\mathrm{a}}$ \\
\hline 4 & $2.60 \pm 0.52^{\mathrm{a}}$ & $3.00 \pm 0.00^{\mathrm{a}}$ & $2.40 \pm 0.84^{\mathrm{a}}$ & $2.20 \pm 0.42^{b, c}$ & $10.20 \pm 1.55^{\mathrm{a}}$ \\
\hline
\end{tabular}

Values are means \pm SD. Whereas differences between values marked with identical letters are not statistically significant, the other differences are significant. $\mathrm{p}<0.01$. teract their antigenic properties and prevent transmission of infection $[16,17]$. Since they cause a hypersensitivity reaction in the host, obstruction develops in the vessels formed between donor tissue and host bed and sequestration in the graft. This, in turn, causes resorption of transplanted bone graft and results in delayed replacement by the new bone, thus restricting their use [5]. As they are relatively easy to obtain, xenografts may find wider usage if their drawbacks can be eliminated.

Burwell [18] found that when live autologous bone marrow cells are combined with foreign bone, they have a high osteogenic potential. Some experimental and clinical trials performed after this development have shown that impregnation of various types of bone graft with autologous red marrow has had beneficial effects on osteogenesis [10, 11, 16, 19-22].

It has been shown in several clinical and experimental studies that treatment of bony defects and some other bone pathologies with a combination of autologous bone marrow and xenograft produced good results $[10,16,19-$ 22]. In this study, no significant difference was found with respect to radiological findings between the groups during the first 15 days of the grafting. However, the results of rabbits treated with a combination of bone marrow and xenograft from the first month indicated that the bony defect was filled with new bone, and resistance against tensile strength as well as histological union criteria of the newly developed bone was much better than in those treated with only xenograft, while there was no statistically significant difference compared to rabbits treated with autogenous bone graft. These findings indicate that the drawbacks of xenografts are significantly compensated when combined with bone marrow. The antigenic properties of xenografts have been reduced a great deal by modern chemical cleaning procedures and some studies using modern immunologic techniques have shown that xenografts are only slightly antigenic $[23,24]$. It may be that combining xenograft with autologous red marrow provides a benefical effect on osteogenesis. Spongy xenograft bone might provide a good medium for osteogenesis by marrow cells. It is most likely that the low-level antigenicity of the xenograft might have interfered with but did not totally prevent the new formation.

Some investigators have argued that percutaneous injection of bone marrow some time after the grafting procedure gives better results compared to simultaneous injection with grafting $[25,26]$. In this study, however, no significant difference was found between the group with simultaneous injection and the group with injection performed 5 days following the grafting. This finding is only valid provided that no bone marrow is allowed to leak. The porous structure of cancellous donor bone prevents bone marrow leaking outside the wound to some extent. It is possible that when the soft tissues over the bone marrow are repaired properly, timing of the bone marrow injection is not important. Bone injection 5 days after treatment with cancellous bone requires a second operation. Surely, this is a serious disadvantage that should be pointed out.

In rabbits, formations of bone and cartilage are easier and faster than in humans. However, Heiple et al. [14] have shown that a defect 1.5 times as long as the diameter of the shaft of the long bone in the adult animal would 
produce a nonunion. In addition, a high degree of nonunion resulted from such defects when filled with bone grafting materials of low osteogenic potential. Therefore, 1-cm-long bony defects were created approximately twice as long as the diameter of the ulnas of the rabbits. The rabbit model used and the methods employed may not be sufficient to prove the superiority of autogenous bone grafts, but it is evident that the addition of red bone marrow has markedly improved the success rate of xenografts.

\section{Conclusion}

In rabbits, for treatment of bony defects, the outcome is not successful enough when xenografts are used alone. Successful outcome can be achieved when xenografts are used in conjunction with autologous red bone marrow, which was easily obtained from rabbits.

\section{Acknowledgments}

This study was approved by the Ethics Council, Medical School of Atatürk University, and by the Research Center of Atatürk University, Turkey.

\section{References}

1 Lane JM, Sandhu HS: Current approaches to experimental bone grafting. Orthop Clin North Am 1987;18:213-225.

2 Schemitsch EH, Bhandari M: Bone healing and grafting; in Koval KJ (ed): Orthopaedic Knowledge. Update 7. Rosemont, The American Academy of Orthopaedic Surgeons, 2002, pp 19-29.

-3 Finkemeier CG: Current concepts review: bone-grafting and bone-graft substitutes. J Bone Joint Surg Am 2002;84:454-464.

4 Laurie SW, Kaban LB, Mulliken JB, Murray JE: Donor-site morbidity after harvesting rib and iliac bone. Plast Reconstr Surg 1984;73: 933-938.

5 Urist MR: Bone transplants and implants; in Urist MR (ed): Fundamental and Clinical Physiology of Bone. Philadelphia, Lippincott, 1980, p 331.

6 Connolly JF, Guse R, Lippiello L, Dehne R: Development of an osteogenic bone-marrow preparation. J Bone Joint Surg Am 1989;71: 684-691.

7 Connolly JF: Clinical use of marrow osteoprogenitor cells to stimulate osteogenesis. Clin Orthop Relat Res 1998;355:S257-S266.

$>8$ Garg NK, Gaur S: Percutaneous autogenous bone-marrow grafting in congenital tibial pseudarthrosis. J Bone Joint Surg Br 1995;77: 830-831.

-9 Sharma S, Garg NK, Veliath AJ, Subramanian S, Srivastava KK: Percutaneous bonemarrow grafting of osteotomies and bony defects in rabbits. Acta Orthop Scand 1992; 63:166-169.
10 Salama R, Burwell RG, Dickson IR: Recombined grafts of bone and marrow: the beneficial effect upon osteogenesis of impregnating xenograft (heterograft) bone with autologous red marrow. J Bone Joint Surg Br 1973;55:402-417.

11 Burwell RG: The function of bone marrow in the incorporation of a bone graft. Clin Orthop Relat Res 1985;200:125-141.

12 Orii $\mathrm{H}$, Sotome S, Chen J, Wang J, Shinomiya K: Beta-tricalcium phosphate (beta TCP) graft combined with bone marrow stromal cells (MSCs) for posterolateral spine fusion. J Med Dent Sci 2005;52:51-57.

$13 \mathrm{Wu}$ W, Chen X, Mao T, Chen F, Feng X: Bone marrow-derived osteoblasts seeded into porous beta-tricalcium phosphate to repair segmental defect in canine's mandibula. Ulus Travma Acil Cerrahi Derg 2006;12: 268-276.

14 Heiple KG, Golberg VM, Powell AE, Bos GD, Zika JM: Biology of cancellous bone grafts. Orthop Clin North Am 1987;18:179-185.

15 Bauer TW, Muschler GF: Bone graft materials: an overview of the basic science. Clin Orthop Relat Res 2000;371:10-27.

16 Gupta D, Khanna S, Tuli SM: Bridging large bone defects with a xenograft composited with autologous bone marrow: an experimental study. Int Orthop 1982;6:79-85.
17 Cooke FW: Ceramics in orthopedic surgery. Clin Orthop Relat Res 1992;276:135-146.

18 Burwell RG: A study of homologous cancellous bone combined with autologous red marrow after transplantation to a muscular site. J Anat 1961;95:613.

19 Salama R, Weissman SL: The clinical use of combined xenografts of bone and autologous red marrow: a preliminary report. J Bone Joint Surg Br 1978;60:111-115.

20 Plenk H Jr, Hollmann K, Wilfert KH: Experimental bridging of osseous defects in rats by the implantation of Kiel bone containing fresh autologous marrow. J Bone Joint Surg Br 1972;54:735-743.

21 Horowitz I, Bodner L: Use of xenograft bone with aspirated bone marrow for treatment of cystic defect of the jaws. Head Neck 1989;11: 516-523.

22 Salama R: Xenogeneic bone grafting in humans. Clin Orthop Relat Res 1983;174:113121.

23 Elves MW, Salama R: A study of the development of cytotoxic antibodies produced in recipients of xenografts (heterografts) of iliac bone. J Bone Joint Surg Br 1974;56:3319.

24 Salama R, Gazit E: The antigenicity of Kiel bone in the human host. J Bone Joint Surg Br 1978;60:262-265.

-25 Amler MH: The lag phase factor in bone healing and suggested application to marrow grafting. J Periodontal Res 1981;16:617-627.

26 Bassett CA: Clinical implications of cell function in bone grafting. Clin Orthop Relat Res 1972;87:49-59. 